\title{
ESTUDOS
}

\section{A educação nas constituições brasileiras: texto e contexto}

Sofia Lerche Vieira

\begin{abstract}
Resumo
Analisa a educação nas diversas constituições brasileiras, detendose sobre elementos do contexto onde estas são concebidas. Apresenta considerações sobre o conjunto dos textos, buscando elucidar aspectos comuns e diferenças marcantes. Evidencia que a presença da educação nas constituições relaciona-se com o seu grau de importância ao longo da história. Enquanto nas primeiras constituições (1824 e 1891) as referências são escassas, a presença de artigos relacionados com o tema cresce significativamente nos textos posteriores (1934, 1937, 1946, 1967 e 1988). As constituições expressam desejos de reforma da sociedade, apontando possibilidades sem assegurar garantias. Ao mesmo tempo, reforçam privilégios de grupos que fazem valer seus interesses junto ao Legislativo. O aprofundamento do tema permite apreciar o contraditório movimento da educação enquanto um valor que passa a incorporar-se aos anseios sociais sem, contudo, oferecer a cidadania plena. Do mesmo modo, permite melhor situar as reformas de educação propostas ao longo da história.

Palavras-chave: constituições brasileiras; política educacional; reforma educacional; história da educação.
\end{abstract}




\section{Abstract}

\section{The education in the brazilian constitutions: text and context}

The work analyses the education in the diverse Brazilian constitutions, focusing on elements of the context in which they are conceived. Considerations on the set of the texts are presented, elucidating common aspects and remarkable differences. The analysis evidences that the presence of the education in the constitutions becomes related with its degree of importance throughout history. While in the first constitutions (1824 and 1891) the references are scarce, the articles related with the subject grow significantly in posterior texts (1934, 1937, 1946, 1967 and 1988). The constitutions express a desire to reform the society, pointing out possibilities without assuring guarantees. At the same time, they strengthen privileges of groups that validate their interests together with the Legislative Power. The deepening of the subject allows to appreciate the contradictory movement of the education while a value that becomes incorporated to the social yearnings without, however, offering full citizenship. In a similar way, it better allows to point out the education reforms proposals throughout history.

Keywords: brazilian constitutions, educational policies, educational reform, history of education.

\section{Introdução}

A análise das constituições ora apresentada insere-se no âmbito da pesquisa Desejos de reforma: inventário da legislação educacional - Brasil e Ceará (Vieira, 2006a). ${ }^{1}$ O trabalho tem por objetivo proceder a um levantamento das principais leis de reforma no País e no referido Estado, detendose sobre documentos marcantes da história da política educacional no Império e na República.

Na perspectiva da pesquisa, as constituições brasileiras são compreendidas como documentos-chave para compreender o contexto e os temas relevantes dos diferentes momentos históricos. Do mesmo modo, sinalizam (ou não) a agenda de reformas que vão sendo propostas ao longo do tempo. Assim sendo, estudá-las é não apenas oportuno como necessário ao conhecimento da temática que se quer desvendar.

As constituições têm-se revelado um tema preferencial de pesquisa no campo da educação. Tais estudos abordam desde aspectos mais gerais (Costa, 2002), sua evolução (Fávero, 1996; Martins, 1996), Constituintes e constituições específicas (Oliveira, 1990; Cury, 2001, 2003), constituições estaduais (Catani, Oliveira, 1993; Vieira, 2006b), para citar apenas alguns.

O significativo número de incursões ilustra o valor dos textos constitucionais na análise da política educacional em nosso país. Tais contribuições,

\footnotetext{
${ }^{1}$ Pesquisa desenvolvida com apoio financeiro do Conselho Nacional de Desenvolvimento Científico e Tecnológico (CNPq) e da Fundação Cearense de Apoio ao Desenvolvimento Científico e Tecnológico (Funcap). A autora agradece a Maria do Socorro Sales Felipe Bezerra, Priscila Holanda Costa e Rosalina Rocha Araújo Moraes, bolsistas de iniciação científica do projeto, a colaboração na organização de dados relativos a este trabalho.
} 
porém, não esgotam o manancial desses textos; deixam abertas outras possibilidades de investigação, entre elas o aprofundamento da articulação passado-presente (eixo diacrônico) e dos nexos texto-contexto (eixo sincrônico) desses discursos.

A interpretação dos textos legais requer uma compreensão do cenário mais amplo onde as decisões sobre os rumos da política educacional são forjadas (Saviani, 1976). Assim como as reformas, também os textos das constituições merecem ser interpretados à luz dos contextos em que são produzidos. Neles, não raro estão razões que ultrapassam a vontade dos legisladores, assim como explicações para mudanças (ou permanências) macroestruturais que determinam boa parte das circunstâncias do fazer educativo.

Este ensaio apresenta uma reflexão acerca dos dispositivos sobre educação nas diversas constituições brasileiras, detendo-se sobre elementos do contexto onde estas são concebidas. O estudo focalizará cada uma das sete cartas magnas, procurando situá-las a partir de um cenário político e educacional. Feito tal movimento, serão apresentadas considerações sobre o conjunto dos textos, buscando elucidar aspectos comuns e diferenças marcantes.

\section{Constituição de 1824}

A primeira Constituição brasileira data do Império, tendo sido promulgada por Dom Pedro I. Retrata o momento político subseqüente à Independência, quando os anseios de autonomia convivem com idéias advindas da antiga Colônia.

Uma das frentes de embates do período se dá na elaboração da primeira Carta Magna. Convocada em junho de 1822, a Assembléia Geral Constituinte e Legislativa para o Reino do Brasil é efêmera. Em busca de preservar seu próprio poder, o imperador a dissolve e convoca um Conselho de Estado para refazer o projeto.

A Constituição de 1824 estabelece princípios de um liberalismo moderado expressando a busca de separação entre Colônia e Metrópole, processo marcado por ambigüidades e contradições. O fortalecimento da figura do imperador se concretiza através do Poder Moderador, garantindo-lhe ampla margem de intervenção na vida pública do País, inclusive na nomeação dos presidentes das províncias (Iglesias, 1985).

O Legislativo é organizado por meio do Senado e da Câmara de Deputados. Os senadores são vitalícios; os Deputados são eleitos por voto indireto e censitário, por eleitores representados apenas pelos homens livres.

Essa Constituição foi a de mais longa vigência em toda a história das constituições brasileiras, tendo orientado o ordenamento jurídico do País por 65 anos. Regulamentou de maneira estável a vida institucional nas diversas crises e turbulências atravessadas no Império. Foi substituída apenas em 1891, com o advento da República. 


\section{Educação na Constituição de 1824}

Com a proclamação da Independência e fundação do Império do Brasil, em 1822, inicia-se uma fase de debates e projetos que visavam a estruturação de uma educação nacional. Com a abertura da Assembléia Legislativa e Constituinte, em 3 de maio de 1823, D. Pedro referiu-se à necessidade de uma legislação particular sobre a instrução. Abertas as sessões da Constituinte e eleita a Comissão de Instrução Pública, os trabalhos desenvolvidos nos seis meses de seu funcionamento produziram dois projetos de lei referentes à educação pública. Embora esse debate tenha sido intenso, em virtude da dissolução da Constituinte de 1823, não veio a traduzir-se em dispositivos incorporados à Constituição de 1824. A primeira Carta Magna brasileira traz apenas dois parágrafos de um único artigo sobre a matéria. Ao tratar da "inviolabilidade dos direitos civis e políticos dos cidadãos brasileiros", estabelece que "A instrução primária é gratuita a todos os cidadãos" (art. 179, § 32). A segunda referência diz respeito aos "Colégios e universidades, onde serão ensinados os elementos das ciências, belas letras e artes" (art. 179, § 33).

A presença desses dois únicos dispositivos sobre o tema no texto de 1824 é um indicador da pequena preocupação suscitada pela matéria educativa naquele momento político. É de se ressaltar, entretanto, a referência à idéia de gratuidade da instrução primária para todos, tema não contemplado pela Lei de 15 de outubro de 1827 ou pela primeira Constituição republicana, de 1891, a ser detalhada adiante. Não deixa de surpreender que, mesmo no nível das expectativas, a República silencie sobre tema acerca do qual o Império se pronuncia.

Como se vê, no contexto do nascente Império, o texto constitucional passa ao largo da matéria educacional, muito embora o Brasil tenha sido um dos primeiros países a inscrever em sua legislação a gratuidade da educação a todos os cidadãos, apesar de esta não ter se efetivado na prática (Oliveira, Adrião, 2002). O momento de maior destaque para a educação no período - a promulgação da Lei de 1827 - é posterior à Carta de 1824, não tendo com esta uma relação direta. Torna-se clara, assim, a pequena relevância do tema para os constituintes sob o jugo da autoridade do primeiro imperador.

\section{Constituição de 1891}

A Constituição de 1891 é produto do alvorecer de uma República marcada por contradições. Proclamada pelo Exército, tendo à frente um monarquista, desde seu nascedouro esta é assinalada por conflitos entre deodoristas e florianistas, que representam os dois segmentos das forças militares que tomam o poder.

A Assembléia Nacional Constituinte é instalada no primeiro aniversário da proclamação da República, sendo a nova Constituição promulgada em 
fevereiro de 1891. Os princípios federalistas nela inscritos buscam aumentar a autonomia das antigas províncias. A força do poder central se mantém pela hegemonia política, enquanto os Estados exercem controle sobre a máquina administrativa. Além disso, é eliminado o Poder Moderador e são mantidos os três poderes tradicionais. Institui-se o voto direto, descoberto e reservado aos homens maiores de 21 anos e a separação entre Estado e Igreja.

A passagem do Império para a República faz emergir anseios de um novo projeto para a educação. Nesse contexto é proposta a Reforma Benjamin Constant, que aprova os Regulamentos da Instrução Primária e Secundária do Distrito Federal, do Ginásio Nacional (Decretos nº 981/90 e nº 1.075/90, respectivamente) e do Conselho de Instrução Superior (Decreto $\left.\mathrm{n}^{\mathrm{0}} 1.232-\mathrm{G} / 91\right)$.

\section{Educação na Constituição de 1891}

A Constituição de 1891 apresenta maior número de dispositivos sobre educação que o texto de 1824, mas ainda não chega a ser pródiga. Mesmo assim, sua importância é significativa para a educação, explicitando alguns temas que irão estar presentes ao longo da história. Como signo fundante da República, traz inscrita em seu texto a bandeira da laicidade, assim como a separação entre os poderes. Vejamos um pouco mais de perto os artigos de interesse direto para o campo educacional.

A nova Carta Magna define como atribuição do Congresso Nacional "legislar sobre [...] o ensino superior e os demais serviços que na capital forem reservados para o Governo da União" (art. 34, inciso 30); suas responsabilidades limitam-se à esfera da União. Tem ainda a incumbência de "não privativamente: animar, no País, o desenvolvimento das letras, artes, e ciências [...] sem privilégios que tolham a ação dos governos locais, criar instituições de ensino superior e secundário nos Estados e prover à instrução primária e secundária no Distrito Federal" (art. 35, incisos $2^{\circ}, 3^{\circ}$ e $4^{\circ}$ ). Aqui é importante assinalar que o texto de 1891 afirma uma tendência que vai se manter constante na história da política educacional.

Palavras como "animar" e "não tolher" referendam o tom federalista antes aludido, revelando, ainda que de forma indireta, as atribuições da União em matéria de educação: o ensino superior no País e a instrução primária e secundária no Distrito Federal. Esta inovação do texto de 1891 em relação ao de 1824 traduz uma primeira marca que chegaria para ficar em um sistema educacional cujo embrião se definira no Império através do Ato Adicional de 1834. Segundo Cury (2001), as condições para a satisfação da educação como "um direito de cidadania ficará por conta dos estados federados", que "determinarão a natureza, o número e a abrangência da educação pública".

A "dualidade dos sistemas", traduzida na configuração de um sistema federal integrado pelo ensino secundário e superior, ao lado de sistemas 
estaduais, com escolas de todos os tipos e graus, estimularia a reprodução de um sistema escolar organizado em moldes tradicionais e de base livresca. Não há ainda no País uma mentalidade de pesquisa, embora se possa dizer que a Reforma Benjamin Constant evidencie uma preocupação mais ostensiva com a formação científica.

Caracterizada pela separação entre Estado e Igreja, a nova Carta traz como grande inovação a laicidade do ensino, ao dispor que seria "leigo o ensino ministrado nos estabelecimentos públicos" (art. 72, § 6º). Também este artigo introduz uma temática que estará presente ao longo da história, assinalando a diferença entre católicos e liberais, questão que se aprofundará no curso da República.

Um último aspecto a mencionar é a proibição do voto aos analfabetos (art. 70, § $1^{\circ}$ ), revelando uma exclusão do direito à cidadania que somente será superada pela Constituição de 1988.

\section{Constituição de 1934}

O fértil período representado pelos anos trinta é preparado pelos movimentos sociais da década anterior, a exemplo da fundação do Partido Comunista do Brasil (1922) e das Revoltas Tenentistas (1922 e 1924), que traduzem insatisfações contra as oligarquias e o sistema republicano vigente. Com Getúlio Vargas no poder, a efervescência política se materializa na Revolução Constitucionalista de 1932. No campo econômico, em reação à crise de 1929, busca-se a substituição de importações como alternativa ao desenvolvimento industrial.

O momento também é rico para a educação. Vários Estados deflagram reformas (Ceará, Pernambuco, Bahia, Rio de Janeiro, São Paulo e Minas Gerais). Cria-se o Ministério de Educação e Saúde (1930), sendo seu primeiro dirigente Francisco Campos, jurista e político mineiro. Sua ação orientase para a reforma do ensino superior e secundário. No campo do ideário pedagógico é forte a influência do escolanovismo, traduzido no Manifesto dos Pioneiros da Escola Nova (1932), marco referencial importante do pensamento liberal com repercussões sobre idéias e reformas propostas em momentos subseqüentes.

\section{Educação na Constituição de 1934}

A Carta de 1934 é a primeira a dedicar espaço significativo à educação, com 17 artigos, 11 dos quais em capítulo específico sobre o tema (cap. II, arts. 148 a 158). Em linhas gerais, mantém a estrutura anterior do sistema educacional, cabendo à União "traçar as diretrizes da educação nacional" (art. 50, XIX), "fixar o plano nacional de educação, compreensivo do ensino de todos os graus e ramos, comuns e especializados, organizar e manter" os sistemas educativos dos Territórios e manter o ensino secundário e superior 
no Distrito Federal (art. 150), assim como exercer "ação supletiva na obra educativa em todo o País" (art. 150, "d" e "e").

A organização e manutenção de sistemas educativos permanecem com os Estados e o Distrito Federal (art. 151). Entre as normas estabelecidas para o Plano Nacional de Educação estão o "ensino primário integral e gratuito e de freqüência obrigatória extensivo aos adultos e tendências à gratuidade do ensino ulterior ao primário, a fim de o tornar mais acessível" (art. 150, parágrafo único, "a" e "b").

Ao lado de idéias liberais, o texto constitucional também expressa tendências conservadoras, favorecendo o ensino religioso "de freqüência facultativa [...] nas escolas públicas primárias, secundárias, profissionais e normais" (art. 153). Tais influências também estão presentes no apoio irrestrito ao ensino privado através da isenção de tributos a quaisquer "estabelecimentos particulares de educação gratuita primária ou profissional, oficialmente considerados idôneos" (art. 154).

Importante matéria do texto é o financiamento da educação. Pela primeira vez são definidas vinculações de receitas para a educação, cabendo à União e aos municípios aplicar "nunca menos de dez por cento e os Estados e o Distrito Federal nunca menos de vinte por cento, da renda resultante dos impostos na manutenção e no desenvolvimento do sistema educativo" (art. 156). Nos mesmos termos é estabelecida a reserva de parte dos patrimônios da União, dos Estados e do Distrito Federal para a formação de fundos de educação (art. 157). São ainda atribuídas responsabilidades relativas às empresas com mais de 50 empregados na oferta de ensino primário gratuito (art. 139).

Outros destaques do texto de 1934 são: as normas do Plano Nacional de Educação, prevendo "liberdade de ensino em todos os graus e ramos observadas as prescrições da legislação federal e da estadual e reconhecimento dos estabelecimentos particulares de ensino somente quando assegura a seus professores a estabilidade, enquanto bem servirem, e uma remuneração condigna" (art. 150, parágrafo único, "c" e "f"); a oferta do ensino em língua pátria (art. 150, "d"); a proibição do voto aos analfabetos (art. 108). Finalmente, vale citar dispositivos relativos ao magistério: a isenção de impostos para a profissão de professor (art. 113, inciso 36) e a exigência de concurso público como forma de ingresso ao magistério oficial (art. 158).

\section{Constituição de 1937}

Se com Vargas no poder o País progressivamente volta a mergulhar em novo período autoritário, o momento histórico corresponde ao início de um processo de mudanças de amplo espectro, a partir das quais são construídas as bases para a modernização do Estado brasileiro. São criados o Ministério do Trabalho, Indústria e Comércio (1931) e a Companhia Siderúrgica Nacional (1941). Direitos trabalhistas são assegurados, por meio da Consolidação das Leis do Trabalho (1943). 
No campo da educação, o Estado Novo corresponde a uma retomada da centralização. Se nos anos anteriores a autonomia dos Estados florescera com o surgimento de vários movimentos reformistas, o início dos anos quarenta responde por reformas educacionais desencadeadas pelo poder central, especificamente as chamadas Leis Orgânicas de Ensino, concebidas durante a administração de Gustavo Capanema no Ministério da Educação. Estas eram integradas por seis decretos-leis, efetivados de 1942 a 1946, como se verá adiante.

\section{Educação na Constituição de 1937}

De orientação oposta ao liberal texto de 1934, a Constituição do Estado Novo é claramente inspirada nas constituições de regimes fascistas europeus. Amplia-se a competência da União para "fixar as bases e determinar os quadros da educação nacional, traçando as diretrizes a que deve obedecer a formação física, intelectual e moral da infância e da juventude" (art. 15, IX).

A liberdade de ensino ou, melhor dizendo, a livre iniciativa é objeto do primeiro artigo dedicado à educação no texto de 1937, que determina: "A arte, a ciência e o ensino são livres à iniciativa individual e à de associações ou pessoas coletivas públicas e particulares" (art. 128). O dever do Estado para com a educação é colocado em segundo plano, sendo-lhe atribuída uma função compensatória na oferta escolar destinada à "infância e à juventude, a que faltarem os recursos necessários à educação em instituições particulares" (art. 129). Nesse contexto, o "ensino pré-vocacional e profissional destinado às classes menos favorecidas" é compreendido como "o primeiro dever do Estado" em matéria de educação (art. 129).

É clara a concepção da educação pública como aquela destinada aos que não puderem arcar com os custos do ensino privado. O velho preconceito contra o ensino público presente desde as origens de nossa história permanece arraigado no pensamento do legislador estado-novista.

Sendo o ensino vocacional e profissional a prioridade, é flagrante a omissão com relação às demais modalidades de ensino. A concepção da política educacional no Estado Novo estará inteiramente orientada para o ensino profissional, para onde serão dirigidas as reformas encaminhadas por Gustavo Capanema.

À idéia de gratuidade da Constituição de 1934 o texto de 1937 contrapõe uma concepção estreita e empobrecida. Embora estabeleça que "o ensino primário é obrigatório e gratuito" (art. 130), acrescenta no mesmo artigo o caráter parcial dessa gratuidade que "não exclui o dever de solidariedade dos menos para com os mais necessitados; assim, por ocasião da matrícula, será exigida aos que não alegarem, ou notoriamente não puderem alegar escassez de recursos, uma contribuição módica e mensal para a caixa escolar". A educação gratuita é, pois, a educação dos pobres.

Também em matéria de ensino religioso, a Constituição de 1937 assinala uma tendência conservadora no dispositivo que permite que este ensino se 
apresente como "matéria do curso ordinário das escolas primárias, normais e secundárias", muito embora não deva se "constituir objeto de obrigação dos mestres ou professores, nem de freqüência compulsória por parte dos alunos" (art. 133). A ambigüidade do texto é óbvia, deixando margem a um facultativo, que acabou por tornar-se compulsório, em se considerando a hegemonia da religião católica sobre as demais, bem como a expressiva presença de escolas confessionais no cenário brasileiro.

\section{Constituição de 1946}

No início da década de quarenta, a sustentabilidade da ditadura Vargas já não é a mesma, em decorrência do cenário agravado pela Segunda Guerra Mundial. Insatisfações contra a ditadura se avolumam tanto entre militares que se opõem ao governo como em manifestos de categorias profissionais. Aos poucos consolidam-se as condições que vão levar o país à redemocratização.

A queda da ditadura do Estado Novo ocorre em final de 1945. Embora Vargas afaste-se do poder, a ordem getulista se mantém. O presidente eleito, general Eurico Gaspar Dutra, de início revela-se um moderado. Assume o poder em janeiro de 1946, promulgando a nova Constituição, orientada por princípios liberais e democráticos, em setembro do mesmo ano. Restabelece também o estado de direito e a autonomia federativa. Essa ordem inicial, contudo, é rompida pouco depois. Em 1947 ocorre a intervenção em mais de uma centena de sindicatos e é decretada a ilegalidade do Partido Comunista Brasileiro (PCB). No plano econômico o País passa por um período de significativo crescimento da indústria nacional, estimulada por restrições às importações e um regime cambial desfavorável às exportações.

Os anos quarenta caracterizam-se por reformas educacionais que passariam à história como as Leis Orgânicas do Ensino, alusão ao título de cada uma, acrescido da área específica a que se destinam. Embora ultrapassem no tempo a obra do Estado Novo, sob sua vigência são acionados decretosleis referentes ao ensino industrial (Lei Orgânica do Ensino Industrial - Decreto-Lei n ${ }^{\circ}$ 4.073/42), ao secundário (Lei Orgânica do Ensino Secundário Decreto-Lei no 4.244/42) e ao comercial (Lei Orgânica do Ensino Comercial - Decreto-Lei $n^{\circ}$ 6.141/43). Também durante este período é criado o Serviço Nacional de Aprendizagem Industrial (Senai - Decreto-Lei n 4.048/42).

Após a queda de Vargas, em 1945, são propostas medidas relativas ao ensino fundamental (Lei Orgânica do Ensino Primário - Decreto-Lei no 8.529/ 46), ao ensino normal (Lei Orgânica do Ensino Normal - Decreto-Lei $n^{\circ}$ 8.530/46) e ao ensino agrícola (Lei Orgânica do Ensino Agrícola - DecretoLei no 9.613/46). Também é instituído o Serviço Nacional de Aprendizagem Comercial (Senac - Decretos-Lei no 8.621/46 e no 8.622/46). Com a Reforma Capanema o sistema educacional brasileiro não só mantém como acentua o dualismo que distingue a educação escolar das elites daquela ofertada para as classes populares. Suas diretrizes vão orientar a educação nacional 
até a promulgação da primeira Lei de Diretrizes e Bases da Educação Nacional (LDB - Lei no 4.024/61). Esta foi, sem dúvida, expressão da necessidade histórica de estruturação do sistema nacional de educação.

Os primeiros anos da redemocratização são agitados também no campo da educação, revelando elementos de contradição que expressam uma sintonia com o contexto político, antes mencionado. Pode-se dizer que o conceito de democracia limitada também se aplica às idéias pedagógicas que circulam no período. Assim, não é de estranhar a convivência entre tendências conservadoras e liberais, traço marcante do debate traduzido na Constituição de 1946.

\section{Educação na Constituição de 1946}

A Carta Magna de 1946 retoma o espírito da Constituição de 1934, apresentando algumas novidades. É estabelecida a competência da União para "legislar sobre as diretrizes e bases da educação nacional" (art. 5, XV). As constituições anteriores haviam definido atribuições no sentido de "traçar as diretrizes" (Constituição de 1934) ou "fixar as bases [...] traçando as diretrizes" (Constituição de 1937).

O texto de 1946 faz ressurgir o tema da educação como direito de todos. Não há, entretanto, um vínculo direto entre esse direito e o dever do Estado em um mesmo artigo, como ocorrera no texto de 1934. Aqui se diz que "o ensino dos diferentes ramos será ministrado pelos Poderes Públicos e é livre à iniciativa particular, respeitadas as leis que o regulem" (art. 167). Outro aspecto importante é a determinação de que "O ensino primário oficial é gratuito para todos: o ensino oficial ulterior ao primário sê-lo-á para quantos provarem falta ou insuficiência de recursos" (art. 168, II).

É a primeira vez que a expressão ensino oficial aparece em um texto legal. O registro tem sentido, por colocar um elemento adicional de diferenciação entre o ensino "ministrado pelos Poderes Públicos" e aquele "livre à iniciativa particular". Há, ainda, outro aspecto a destacar com referência ao termo ensino oficial. Parece colocar-se aqui a possibilidade do ensino oficial não gratuito, pois a Constituição estabelece que a instrução subseqüente à primária somente seja gratuita para aqueles que "provarem falta ou insuficiência de recursos".

O ensino religioso, fonte adicional para uma compreensão dos embates entre católicos e liberais, assegura seu espaço no texto, através da orientação de que "o ensino religioso constitui disciplina dos horários das escolas oficiais, e é de matrícula facultativa e será ministrado de acordo com a confissão religiosa do aluno, manifestada por ele, se for capaz, ou pelo seu representante legal ou responsável" (art. 168, V).

Como se vê, a laicidade não é assegurada nas escolas oficiais. Por outro lado, há uma conquista formal na determinação de que a religião seja ministrada de acordo com as confissões de cada um, muito embora seja impossível aquilatar se religiões não-católicas puderam penetrar livremente nas escolas oficiais. 
Entre outros dispositivos a destacar no texto de 1946, cabe lembrar ainda a novidade da vinculação de recursos para a educação, estabelecendo que a União deva aplicar nunca menos de 10\% e Estados, Municípios e Distrito Federal, nunca menos de 20\% das receitas resultantes de impostos na "manutenção e desenvolvimento do ensino" (art. 169). Ainda em matéria financeira, é de se observar que a União deve colaborar com o desenvolvimento dos sistemas de ensino, prestando "auxílio pecuniário", que, no caso do ensino primário, "provirá do respectivo Fundo Nacional" (art. 171, parágrafo único).

Na organização da educação escolar mantém-se a orientação de que os Estados e o Distrito Federal organizem seus "sistemas de ensino" (art. 171), cabendo à União organizar o "sistema federal de ensino e o dos Territórios, tendo este um caráter supletivo, estendendo-se a todo o País nos estritos limites das deficiências locais" (art. 170). Como se vê, prevalece a organização escolar que remonta à origem das primeiras determinações legais sobre a administração da educação, característica que há de permanecer ao longo da construção de um sistema de ensino no País.

\section{Constituição de 1967}

Após vivenciar a experiência da redemocratização, o País volta a mergulhar numa fase marcada pelo autoritarismo. Com o golpe de 1964 viria o fechamento da ordem política por um período superior àquele que, de início, parecia anunciar-se. Somente 20 anos depois da ascensão dos militares ao poder, um novo governo civil seria eleito pelo voto indireto.

Os tempos inaugurados com a ditadura representam uma estratégia de adequação entre o modelo político e o modelo econômico, de base capitalista. Durante o regime militar avançam os processos de urbanização e de industrialização iniciados nos anos trinta e acelerados com o governo Juscelino Kubitschek. Há um aumento significativo da população urbana, a indústria passa a responder por parcela importante do Produto Interno Bruto (PIB), sendo incrementada a produção de bens duráveis.

Depois de uma fase inicial de ajuste estrutural, o ritmo de desenvolvimento acelera-se, ingressando o País na fase do chamado "milagre econômico". Projetos de grande porte são concebidos e realizados, começando o Brasil a ser percebido no rol das grandes potências emergentes.

Sob a égide da ditadura, é concebido um novo marco legal para o País, a começar por uma nova Constituição Federal (1967). Como esta é concebida antes das medidas que instauram o estado de exceção, as características do novo regime nem sempre são visíveis no texto.

No campo da educação, somente depois da Constituição de 1967 é que são encaminhadas as principais propostas de reforma do período. Cabe, porém, uma breve referência a elas, já que marcam de forma decisiva o cenário dos anos subseqüentes. Primeiro, é concebida a reforma do ensino superior (Lei $n^{\circ} 5.540 / 68$ ). Depois toma corpo a reforma da 
educação básica, que fixa as diretrizes e bases para o ensino de $1^{\circ}$ e $2^{\circ}$ graus (Lei n ${ }^{\circ}$ 5.692/71).

A reforma universitária tem por objetivo oferecer resposta às demandas crescentes por ensino superior. Busca, ao mesmo tempo, formar quadros deste nível de modo a dar substância ao crescimento econômico gerado pelo "milagre brasileiro". A reforma do ensino de $1^{\circ}$ e $2^{\circ}$ graus, por sua vez, pretende atingir um duplo objetivo: de um lado, conter a crescente demanda sobre o ensino superior; de outro, promover a profissionalização de nível médio.

Durante os governos militares há uma expressiva subordinação das unidades federadas às decisões tomadas pelo poder central, com aumento da ingerência dos ministérios na esfera dos Estados e adoção de uma sistemática de planejamento estranha à cultura de governo até então existente em nível local. A centralização retorna como marca dominante da gestão pública.

\section{Educação na Constituição de 1967}

Como se viu, a Constituição de 1967 foi concebida num cenário em que a supressão das liberdades políticas ainda não atingira seu estágio mais agudo. Assim, no caso da educação, os dispositivos não chegam a traduzir uma ruptura com conteúdos de constituições anteriores. Antes expressam a presença de interesses políticos já manifestos em outras Cartas, sobretudo àqueles ligados ao ensino particular. A "liberdade de ensino", tema chave do conflito entre o público e o privado desde meados dos anos cinqüenta, é visível no texto produzido no regime militar. Outros temas advindos dos textos nacionais de 1934, 1937 e 1946 são reeditados, fazendo com que nos dispositivos relativos à educação a Constituição de 1967 esteja mais próxima da LDB de 1961 do que da legislação aprovada em pleno vigor do estado de exceção.

Mantendo orientação do texto de 1946 (art. 5 XV), a Constituição de 1967 define a competência da União para legislar sobre diretrizes e bases da educação nacional (art. $8^{\circ}$, XVII, "q"). São acrescidas atribuições relativas aos planos nacionais de educação (art. $8^{\circ}$, XIV). Orientações e princípios de Cartas anteriores são reeditados, tais como: o ensino primário em língua nacional (Constituição de 1946, art. 168, I, e Constituição de 1967, art. $\left.176, \S 3^{\circ}, \mathrm{I}\right)$, a obrigatoriedade e a gratuidade do ensino primário (Constituição de 1946, art. 168, I e II, e Constituição de 1967, art. 176, § 3º II), o ensino religioso, de matrícula facultativa como "disciplina dos horários normais das escolas oficiais de grau primário e médio (Constituição de 1946, art. $168, \S 5^{\circ}$, e Constituição de 1967, art. 176, § $3^{\circ}$, V). À noção de educação como "direito de todos", já presente no texto de 1946 (art. 166), a Constituição de 1967 acrescenta "o dever do Estado" (art. 176).

Nos mesmos termos da Carta de 1946 (art. 167), a Constituição de 1967 determina que o ensino seja "ministrado nos diferentes graus pelos 
poderes públicos" (art. 176, § 1). Embora ambas definam que este seja "livre à iniciativa particular", nota-se, porém, uma importante diferença entre elas. O texto de 1946 observa que devam ser "respeitadas as leis que o regulem" (art. 167), ao passo que a Carta de 1967 avança visivelmente no terreno do subsídio ao ensino privado, uma vez que este "merecerá amparo técnico e financeiro dos Poderes Públicos, inclusive mediante bolsas de estudo" (art. 176, § $2^{\circ}$ ).

Embora outros dispositivos possam ser destacados acerca da matéria na Constituição de 1967, para não detalhá-lo em excesso é oportuno acrescentar apenas mais dois aspectos relativos ao tema do financiamento. Em primeiro lugar, admite-se a "intervenção do Estado no município" que não aplicar "no ensino primário, em cada ano, de vinte por cento, pelo menos da receita tributária municipal" (art. 15).

Em segundo lugar, vale registrar o flagrante retrocesso representado pela desvinculação dos recursos para a educação. Enquanto pela Constituição de 1946, a União estaria obrigada a aplicar "nunca menos de dez por cento, e os Estados, o Distrito Federal e os Municípios nunca menos de vinte por cento da renda resultante dos impostos na manutenção e desenvolvimento do ensino" (art. 169), na Carta de 1967 tal obrigação desaparece. A vinculação seria reeditada muitos anos depois, por força de Emenda Constitucional (EC) aprovada já na década de oitenta. A partir de então, a União é responsável pela aplicação de "nunca menos de treze por cento, e os Estados, o Distrito Federal e os Municípios, vinte e cinco por cento, no mínimo, da receita resultante de impostos na manutenção e desenvolvimento do ensino" (EC n 24/83, art. 176, § 4º).

\section{Constituição de 1988}

Com o progressivo esgotamento do regime militar, iniciado em 1978, o País retoma os anseios pelo estado de direito. Em 1984 há um intenso movimento democrático por eleições diretas. O Congresso Nacional, entretanto, referenda ainda em escolha indireta os nomes de Tancredo Neves para presidente e de José Sarney para vice.

Por motivos de saúde, o presidente eleito falece antes da posse. Em seu lugar assume o vice, que mantém o compromisso de revogar a legislação autoritária por meio de várias medidas, entre elas a eleição de uma Assembléia Nacional Constituinte, encarregada de dar ao País uma nova Carta Magna.

Em termos do cenário educacional, pode-se dizer que o governo José Sarney corresponde a uma fase de indefinição de rumos. Há um debate sobre educação expresso em alguns documentos que traduzem os anseios de mudança do período (Educação para Todos: caminhos para mudança, I Plano de Desenvolvimento da Nova República 1986-1989 e Dia Nacional de Debate sobre Educação). Os instrumentos de política educacional, todavia, continuam os mesmos do período autoritário. Com efeito, a atenção dos educadores converge para a Assembléia Nacional Constituinte, que, mesmo 
antes de ser instalada, recebe contribuições dos atores ligados ao campo educacional, em franco processo de organização desde o início da década.

\section{Educação na Constituição de 1988}

A Constituição de 1988 é a mais extensa de todas em matéria de educação, sendo detalhada em dez artigos específicos (arts. 205 a 214) e figurando em quatro outros dispositivos (arts. 22, XXIV, 23, V, 30, VI, e arts. 60 e 61 do Ato das Disposições Constitucionais Transitórias - ADCT). A Carta trata da educação em seus diferentes níveis e modalidades, abordando os mais diversos conteúdos.

Em sintonia com o momento de abertura política, o espírito do texto é o de uma "Constituição Cidadã" que propõe a incorporação de sujeitos historicamente excluídos do direito à educação, expressa no princípio da "igualdade de condições para o acesso e permanência na escola" (art. 206, I). Outras conquistas asseguradas são: a educação como direito público subjetivo (art. 208, § $1^{\circ}$ ), o princípio da gestão democrática do ensino público (art. 206, VI), o dever do Estado em prover creche e pré-escola às crianças de 0 a 6 anos de idade (art. 208, IV), a oferta de ensino noturno regular (art. 208, VI), o ensino fundamental obrigatório e gratuito, inclusive aos que a ele não tiveram acesso em idade própria (art. 208, I), o atendimento educacional especializado aos portadores de deficiências (art. 208, III).

O espírito da Carta de 1988 está expresso, sobretudo, nos artigos que tratam da concepção, dos princípios e dos deveres do Estado no campo da educação. A noção de educação como direito, que começa a se materializar na Constituição de 1934 (art. 149) e é reafirmada em 1946 e 1967, é reeditada de forma ampla através da afirmação de que "A educação, direito de todos e dever do Estado e da família, será promovida e incentivada com a colaboração da sociedade, visando ao pleno desenvolvimento da pessoa, seu preparo para o exercício da cidadania e sua qualificação para o trabalho" (art. 205).

Os princípios norteadores do ensino são tratados em um mesmo artigo (art. 206). Além daqueles já mencionados antes (art. 206, I e VI), outros cinco assim se expressam: a "liberdade de aprender, ensinar, pesquisar e divulgar o pensamento, a arte e o saber"; o "pluralismo de idéias e de concepções pedagógicas, e coexistência de instituições públicas e privadas de ensino"; a "gratuidade do ensino público em estabelecimentos oficiais"; a "valorização dos profissionais do ensino, garantido, na forma da lei, plano de carreira para o magistério público, com piso salarial profissional e ingresso exclusivamente por concurso público de provas e títulos, assegurado regime jurídico único para todas as instituições mantidas pela União"; e a "garantia de padrão de qualidade" (art. 206, II, III, IV, V e VII).

Outras constituições haviam estabelecido deveres do Estado para com a educação, mas nenhuma avançaria tanto quanto a "Constituição Cidadã". Além daqueles já mencionados, cabe acrescentar: a "progressiva extensão da obrigatoriedade e gratuidade ao ensino médio"; o "acesso aos níveis mais 
elevados do ensino, da pesquisa e da criação artística, segundo a capacidade de cada um"; o "atendimento ao educando, no ensino fundamental, através de programas suplementares de material didático-escolar, transporte, alimentação e assistência à saúde" (art. 208, II, VI e VII, respectivamente). O mesmo artigo dispõe que o "não-oferecimento do ensino obrigatório pelo Poder Público, ou sua oferta irregular, importa responsabilidade da autoridade competente" (art. 208, § $2^{\circ}$ ). Atribui ainda a este a tarefa de "recensear os educandos no ensino fundamental, fazer-lhes a chamada e zelar, junto aos pais ou responsáveis, pela freqüência à escola" (art. 208, § 3).

Esta é a primeira Carta Magna a tratar da autonomia universitária, estabelecendo que "as universidades gozam de autonomia didático-científica, administrativa e de gestão financeira e patrimonial, e obedecerão ao princípio de indissociabilidade entre ensino, pesquisa e extensão" (art. 207).

A Constituição de 1988 mantém a competência privativa da União para "legislar sobre diretrizes e bases da educação nacional" (art. 22, XXIV) e compartilhada com os Estados, o Distrito Federal e os Municípios para "proporcionar os meios de acesso à cultura, à educação e à ciência" (art. 23, V). Aos municípios é atribuída a manutenção, "com a cooperação técnica e financeira da União e do Estado, os programas de educação pré-escolar e de ensino fundamental" (art. 30, VI) e a orientação reforçada na determinação de sua atuação prioritária no ensino fundamental e pré-escolar (art. 211, § $2^{\circ}$ ).

A articulação entre as esferas do Poder Público é expressa na afirmação de que "a União, os Estados, o Distrito Federal e os Municípios organizarão em regime de colaboração seus sistemas de ensino" (art. 211). Nesta perspectiva, cabe à União organizar e financiar "o sistema federal de ensino e o dos Territórios" e prestar "assistência técnica e financeira aos Estados, ao Distrito Federal e aos municípios para o desenvolvimento de seus sistemas de ensino e o atendimento prioritário à escolaridade obrigatória" (art. 211, § 1º).

A vinculação de recursos para a educação recebeu tratamento prioritário, sendo estabelecido que a União aplicaria "anualmente, nunca menos de dezoito, e os Estados, o Distrito Federal e os municípios vinte e cinco por cento, no mínimo, da receita resultante de impostos, compreendida a proveniente de transferências, na manutenção e desenvolvimento do ensino" (art. 212). O mesmo artigo assegura como prioritário na distribuição de recursos públicos o "atendimento das necessidades do ensino obrigatório, nos termos do plano nacional de educação" (art. 212, § 3). Mantém-se como fonte adicional de financiamento a este nível de ensino público "a contribuição social do salárioeducação, recolhida, na forma da lei, pelas empresas, que dela poderão deduzir a aplicação realizada no ensino fundamental de seus empregados e dependentes" (art. 212, § 5º). Ainda sobre a matéria cabe assinalar que o financiamento dos "programas suplementares de alimentação e assistência à saúde" seria advindo de "recursos provenientes de contribuições sociais e outros recursos orçamentários" (art. 212, § 4º).

A "liberdade de ensino", tema predominante em constituições anteriores, é colocada em novos termos na Carta de 1988, que chega a ser módica em relação ao assunto. A ambígua expressão do passado é substituída por 
outra mais próxima do papel reservado ao ensino particular no sistema de ensino brasileiro contemporâneo. Diz-se que "o ensino é livre à iniciativa privada", observando-se o "cumprimento das normas gerais da educação nacional" e a "autorização e avaliação de qualidade pelo poder público" (art. 209, I e II).

Mantém-se a abertura de transferir recursos públicos ao ensino privado. As instituições passíveis de recebê-los são "escolas comunitárias, confessionais ou filantrópicas", as quais devem comprovar "finalidade não lucrativa" e aplicação de "excedentes financeiros em educação", assim como assegurar "a destinação de seu patrimônio a outra escola comunitária, filantrópica ou confessional, ou ao poder público, no caso de encerramento de suas atividades" (art. 212, I e II). A concessão de tais benefícios pode ser feita por meio de "bolsas de estudo para o ensino fundamental e médio, na forma da lei, para os que demonstrarem insuficiência de recursos, quando houver falta de vagas e cursos regulares da rede pública na localidade da residência do educando, ficando o poder público obrigado a investir prioritariamente na expansão de sua rede na localidade" (art. 212, § 1). São também possíveis beneficiárias de apoio financeiro do Poder Público "atividades universitárias de pesquisa e extensão" (art. 212, § $2^{\circ}$ ).

Concluindo o mapeamento das questões relativas à educação na Carta de 1988, cabe ainda mencionar a previsão de lei para estabelecer o plano nacional de educação (art. 214), assim como a concentração de esforços do Poder Público na eliminação do analfabetismo e na universalização do ensino fundamental (ADCT, art. 60).

O Plano Nacional de Educação (PNE), discutido intensamente depois da aprovação da Constituição de 1988 e da Lei de Diretrizes e Bases da Educação Nacional (LDB) de 1996, foi votado pelo Congresso Nacional e aprovado com vetos pelo Presidente da República, através da Lei n 10.172, de 9 de janeiro de $2001 .^{2}$

\section{Para finalizar}

O estudo das constituições é tema relevante para a reflexão sobre a política educacional por várias razões. As cartas magnas são documentos escritos para serem divulgados e incorporados à vida pública; configuramse, portanto, como instrumentos formais de prescrição de regras que contribuíram para a formação de um aparato jurídico no País. Como elementos da administração pública, definem estratégias e registram políticas. Por isso mesmo é importante conhecê-las e analisá-las.

É oportuno assinalar que a presença ou ausência da educação nas constituições brasileiras evidencia seu menor ou maior grau de importância ao longo da história. Nas primeiras constituições (1824 e 1891) as referências são mínimas, ilustrando sua pequena relevância para a sociedade da época. Com o aumento da demanda por acesso à escola, a presença de artigos relacionados com o tema cresce significativamente nas constituições posteriores (1934, 1937, 1946, 1967 e 1988).

\footnotetext{
${ }^{2}$ Veja-se, a propósito, a apresentação de Vital Didonet (Brasil, 2000, p. 11-29).
} 
Entre as referências iniciais ao ensino superior e à gratuidade da instrução primário, da Carta de 1824 e o amplo espectro de temas da Constituição de 1988 há um percurso interessante a observar. As constituições são tributárias dos contextos em que são produzidas, expressando correlações de forças que perpassam a produção das políticas públicas no âmbito do Estado. Assim, se em 1934 idéias liberais aparecem no texto constitucional, em 1937 o movimento é no sentido inverso. Já em 1946 as idéias reformistas voltam a permear as referências à educação. Por outro lado, se alguns temas perpassam o conjunto das constituições, outros são exclusivos de determinados momentos históricos, expressando suas marcas.

Vale observar, também, que existe uma sintonia entre as expectativas mais amplas da sociedade e os conteúdos educacionais que acabam por aparecer nos textos das sete cartas magnas brasileiras. As constituições expressam esses desejos de reforma, apontando possibilidades sem, entretanto, assegurar garantias. Ao mesmo tempo, reforça privilégios de grupos que fazem valer seus interesses junto ao Legislativo, como foi o caso do ensino religioso e do ensino particular. A reflexão sobre esses discursos permite apreciar o contraditório movimento da educação enquanto um valor que passa a incorporar-se aos anseios sociais sem, contudo, oferecer a cidadania plena.

\section{Referências bibliográficas}

BRASIL. Constituições Brasileiras: 1824. vol. I. Brasília: Senado Federal e Ministério da Ciência e Tecnologia, Centro de Estudos Estratégicos, 2001a.

. Constituições Brasileiras: 1891. vol. II. Brasília: Senado Federal e Ministério da Ciência e Tecnologia, Centro de Estudos Estratégicos, 2001b.

Constituições Brasileiras: 1934. vol. III. Brasília: Senado Federal e Ministério da Ciência e Tecnologia, Centro de Estudos Estratégicos, 2001c.

Constituições Brasileiras: 1937. vol. IV. Brasília: Senado Federal e Ministério da Ciência e Tecnologia, Centro de Estudos Estratégicos, 2001d.

Constituições Brasileiras: 1946. vol. V. Brasília: Senado Federal e Ministério da Ciência e Tecnologia, Centro de Estudos Estratégicos, 2001e. 
BRASIL. Constituições Brasileiras: 1967. vol. VI. Brasília: Senado Federal e Ministério da Ciência e Tecnologia, Centro de Estudos Estratégicos, 2001f.

Constituições Brasileiras: 1988. vol. VII. Brasília: Senado Federal e Ministério da Ciência e Tecnologia, Centro de Estudos Estratégicos, 2003.

Plano Nacional de Educação. Apresentação de Vital Didonet. Brasília: Ed. Plano, 2000.

CATANI, Afrânio; OLIVEIRA, Romualdo Portela de. Constituições estaduais brasileiras e educação. São Paulo: Cortez, 1993.

COSTA, Messias. A educação nas Constituições do Brasil: dados e direções. Rio de Janeiro: DP\&A, 2002.

CURY, Carlos Roberto Jamil. Cidadania republicana e educação: governo provisório do marechal Deodoro e Congresso Constituinte de 1890-1891. Rio de Janeiro: DP\&A, 2001.

. A educação na Revisão Constitucional de 1925-1926. Bragança Paulista, SP: Universidade São Francisco, 2003. v. 1.

FÁVERO, Osmar (Org.). A Educação nas Constituições Brasileiras. São Paulo: Cortez, 1996.

IGLESIAS, Francisco. Constituintes e constituições brasileiras. São Paulo: Brasiliense, 1985.

MARTINS, Vicente de Paula da Silva. Constituição e educação: análise evolutiva da educação na organização constitucional do Brasil. Dissertação (Mestrado) - Universidade Federal do Ceará, Fortaleza, 1996.

OLIVEIRA, Romualdo Portela de. Educação e sociedade na Assembléia Constituinte de 1946. Dissertação (Mestrado) - Faculdade de Educação, Universidade de São Paulo, São Paulo, 1990.

OLIVEIRA, Romualdo Portela de; ADRIÃO, Thereza Maria de Freitas (Org.). Gestão, financiamento e direito à educação. São Paulo: Xamã. 2002.

SAVIANI, Dermeval. Análise crítica da organização escolar brasileira através das leis 5.540/68 e 5.692/71. In: GARCIA, Walter (Org.). Educação brasileira contemporânea. São Paulo: McGraw-Hill, 1976. p.174-194. 
VIEIRA, Sofia Lerche. Desejos de reforma: a legislação como fonte de análise da política educacional. In: IV SEMINÁRIO REGIONAL DE POLÍTICA E ADMINISTRAÇÃO DA EDUCAÇÃO DO NORDESTE, 4. Natal, 2006a. Comunicação oral. Artigo completo. CD-ROM.

A educação nas Constituições do Ceará. In: Documentos de política educacional no Ceará: Império e República. v. 1. Brasília: Inep, 2006b. CD-ROM. (Coleção Documentos da Educação Brasileira).

Sofia Lerche Vieira, doutora em Filosofia e História da Educação pela Pontifícia Universidade Católica de São Paulo (PUC-SP), é professora Titular da Universidade Estadual do Ceará (UECE) e pesquisadora do Conselho Nacional de Desenvolvimento Científico e Tecnológico (CNPq).

sofialerche@yahoo.com.br

Recebido em 22 de agosto de 2006.

Aprovado em 23 de abril de 2007. 